\title{
Detection of Synchronous Parathyroid Adenoma and Breast Cancer with ${ }^{18}$ F-Fluorocholine PET-CT
}

\author{
Wessel MCM Vorselaars ${ }^{1}$ - Wouter P. Kluijfhout ${ }^{1} \cdot$ Menno R. Vriens $^{1}$ • \\ Carmen C. van der Pol ${ }^{1}$ • Inne HM Borel Rinkes ${ }^{1}$. Gerlof D. Valk ${ }^{2}$ • \\ Bart de Keizer ${ }^{3}$
}

Received: 13 May 2015 /Revised: 8 July 2015 / Accepted: 21 July 2015 /Published online: 21 August 2015

(C) The Author(s) 2015. This article is published with open access at Springerlink.com

A 71-year-old woman was referred to our tertiary care center for evaluation of asymptomatic recurrence of primary hyperparathyroidism. As per our protocol, the patient underwent neck/mediastinum ${ }^{18} \mathrm{~F}$-fluorocholine (FCH) positron emission tomography-computed tomography (PET-CT) for localization. In our institution, FCH PET-CT is performed in patients with hyperparathyroidism and negative conventional imaging [1]. FCH PET$\mathrm{CT}$ is a promising new imaging modality for detection of hyperfunctioning parathyroid glands [2, 3]. Thirty minutes after injection of $139 \mathrm{MBq}(3.8 \mathrm{mCi})$, the PETCT images showed a focal uptake (SUVmax $=1.8$ ) at the lower anterior neck, level VI, anterior to the right common carotid artery (Fig. 1a-f), suspicious for parathyroid adenoma. Additionally, it showed a second focal uptake $(\mathrm{SUVmax}=2.5)$ in a nodal structure measuring $1.2 \mathrm{~cm}$, within the outer lower quadrant of the right breast (Fig. 2a-f). No other pathological uptake was seen. On

Bart de Keizer

b.deKeizer@umcutrecht.nl

1 Department of Oncological and Endocrine Surgery, University Medical Center Utrecht, Utrecht, The Netherlands

2 Department of Endocrine Oncology, University Medical Center Utrecht, Utrecht, The Netherlands

3 Department of Nuclear Medicine and Radiology, University Medical Center Utrecht, Heidelberglaan 100, 3584

CX Utrecht, The Netherlands the subsequent ultrasound (US) of the breast, there was an area of microcalcifications seen with no definite abnormal lesion. US of the axilla was negative for any suspicious lesions. Mammography showed a blurry $1.3-\mathrm{cm}$ mass without clear boarders and microcalcifications within relatively dense fibroglandular tissue (BI-RADS IV). US-guided core biopsy showed papillary carcinoma. Pathological examination after breast-conserving surgery revealed papillary breast cancer of $1.0 \mathrm{~cm}$, staged pT1N0. The location of the cancer corresponded with that indicated by FCH PET$\mathrm{CT}$. Due to the finding of breast cancer, surgery for primary hyperparathyroidism was postponed.

Currently, mammography and US are considered the standard of care in the preoperative workup of breast cancer [4]. Multiple other imaging modalities, including positron emission mammography (PEM) with a variety of radionuclide tracers as well as magnetic resonance imaging (MRI), are currently under investigation [5-7]. Breast cancer has previously been found to have increased uptake of choline [8]. Therefore, the use of ${ }^{11} \mathrm{C}$-choline PET/CT has been used to accurately localize these malignant tumors [9]. One major drawback is that the half-life of ${ }^{11} \mathrm{C}$-methionine is only $20 \mathrm{~min}$. This requires on-site production of the tracer to be used in the study, thereby strongly limiting its clinical applicability. The half-life of FCH is 110 min, enabling off-site production and distribution, making it much more practical to use as an imaging modality in this context [10]. Furthermore, FCH is already being used in the evaluation of prostate cancer and is therefore more widely available than other radiotracers [11, 12]. 
Fig. $1{ }^{18}$ F-Fluorocholine PET$\mathrm{CT}$ of the neck/mediastinum: axial (a-c) and coronal (d-f) PET, CT and fused PET-CT images showing a focal uptake (SUVmax= 1.8 ) at the lower anterior neck, level VI, anterior to the right common carotid artery, suggesting parathyroid adenoma a

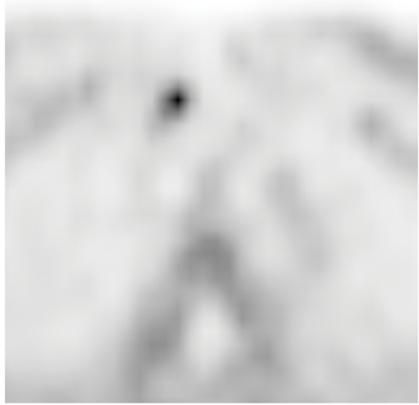

d

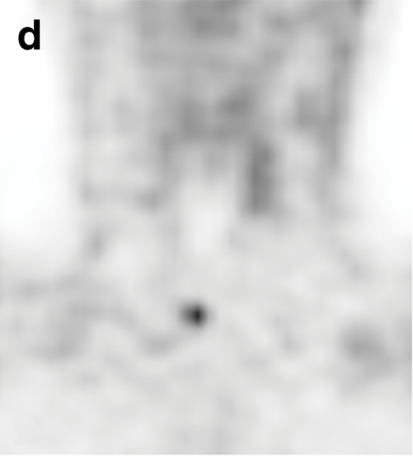

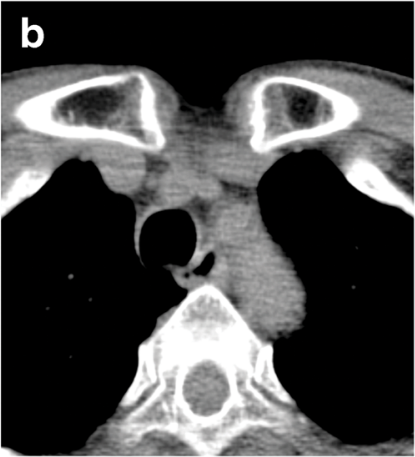
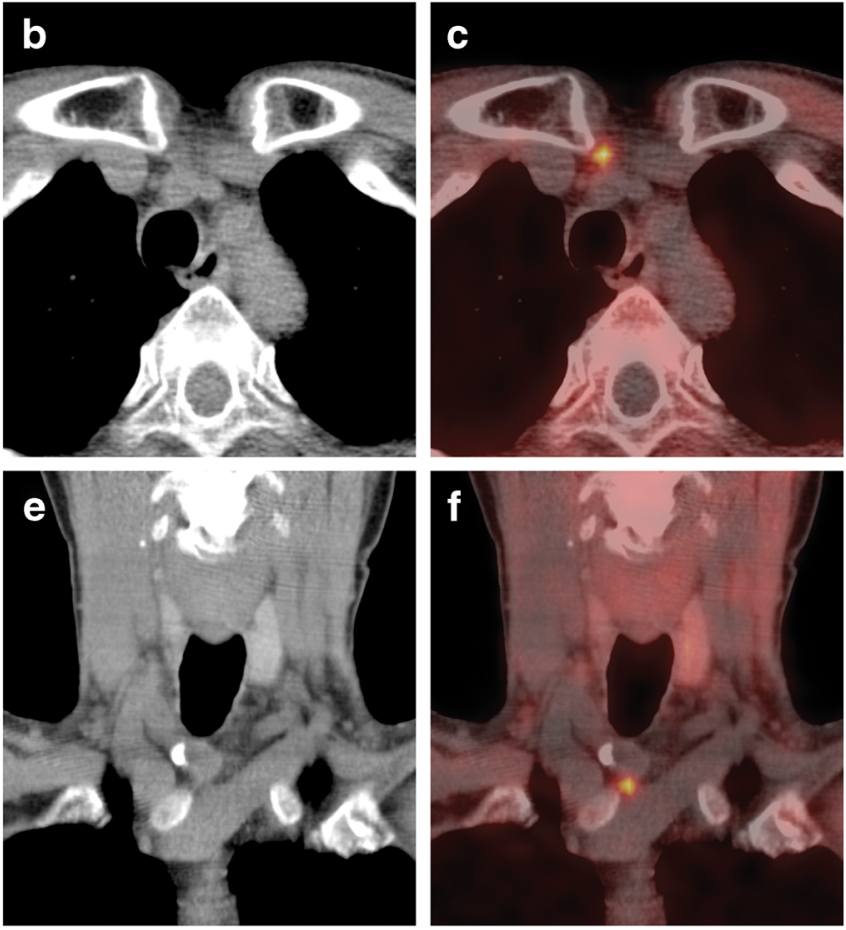

As can be seen in the case presented, high FCH uptake was seen in a small breast cancer. Due to its favorable half-life and wide availability by its use as a localization technique for patients with prostate cancer and complicated hyperparathyroidism, FCH PET-CT may be a new promising modality in the imaging of breast cancer.
Fig. $2{ }^{18}$ F-Fluorocholine PET$\mathrm{CT}$ of the neck/mediastinum: axial (a-c) and coronal (d-f) PET, CT and fused PET-CT images showing an additional focal uptake $(\mathrm{SUVmax}=2.5)$ in a nodal structure of $1.2 \mathrm{~cm}$ located in the lateral lower quadrant of the right breast
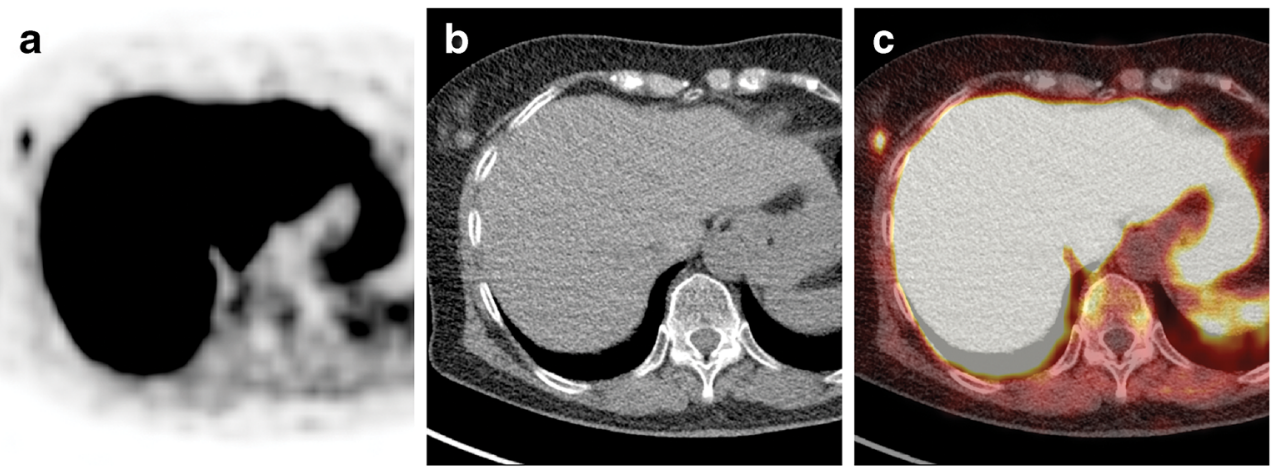

d

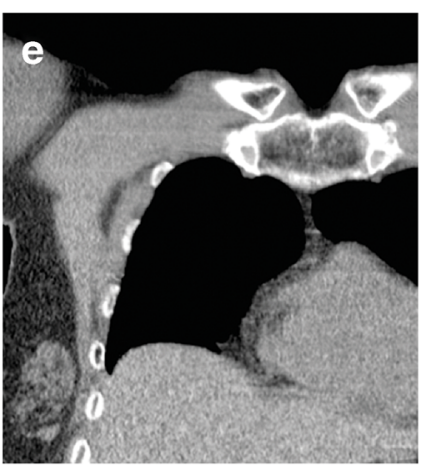


Conflict of interest W.M.C.M. Vorselaars, W.P. Kluijfhout, M.R. Vriens, C.C. van derPol, I.H.M. Borel Rinkes, G.D. Valk and B. de Keizer declare that they have no conflict of interest.

Ethical approval All procedures performed were in accordance with the ethical standards of the institutional and/or national research committee and with the 1964 Helsinki declaration and its later amendments or comparable ethical standards.

Open Access This article is distributed under the terms of the Creative Commons Attribution 4.0 International License (http:// creativecommons.org/licenses/by/4.0/), which permits unrestricted use, distribution, and reproduction in any medium, provided you give appropriate credit to the original author(s) and the source, provide a link to the Creative Commons license, and indicate if changes were made.

\section{References}

1. Kluijfhout WP, Vorselaars WM, Vriens MR, et al. Enabling minimal invasive parathyroidectomy for patients with primary hyperparathyroidism using Tc-99m-sestamibi SPECT-CT, ultrasound and first results of (18)F-fluorocholine PET-CT. Eur J Radiol. 2015. doi:10.1016/j.ejrad.2015.05.024.

2. Michaud L, Burgess A, Huchet V, et al. Is $18 \mathrm{~F}$-fluorocholinepositron emission tomography/computerized tomography a new imaging tool for detecting hyperfunctioning parathyroid glands in primary or secondary hyperparathyroidism? J Clin Endocrinol Metab. 2014;99:4531-6.

3. Lezaic L, Rep S, Sever MJ, et al. ${ }^{18}$ F-fluorocholine PET/CT for localization of hyperfunctioning parathyroid tissue in primary hyperparathyroidism: a pilot study. Eur J Nucl Med Mol Imaging. 2014;41:2083-9.
4. Senkus E, Kyriakides S, Penault-Llorca F, et al. Primary breast cancer: ESMO Clinical Practice Guidelines for diagnosis, treatment and follow-up. Ann Oncol. 2013;24:vi7-vi23.

5. Calderella C, Treglia G, Giordano A. Diagnostic performance of dedicated positron emission mammography using fluorine-18-fluorodeoxyglucose in women with suspicious breast lesions: a meta-analysis. Clin Breast Cancer. 2014;14:241-8.

6. Berg WA, Zhang Z, Lehrer D, et al. Detection of breast cancer with addition of annual screening ultrasound or a single screening MRI to mammography in women with elevated breast cancer risk. JAMA. 2012;307:1394-404.

7. Dorrius MD, de Vries EF, Slart RH, et al. Breast cancer: a new imaging approach as an addition to existing guidelines. Eur J Nucl Med Mol Imaging. 2015;42:813-7.

8. Glunde K, Jie C, Bhujwalla ZM. Molecular causes of the aberrant choline phospholipid metabolism in breast cancer. Cancer Res. 2004;64:4270-6.

9. Contractor KB, Kenny LM, Stebbing J, et al. [11C]choline positron emission tomography in estrogen receptor-positive breast cancer. Clin Cancer Res. 2009;15:5503-10.

10. Kwee SA, DeGrado TR, Talbot JN, et al. Cancer imaging with fluorine-18-labeled choline derivatives. Semin Nucl Med. 2007;37:420-8.

11. Behesthi M, Haim S, Zakavi R, et al. Impact of $18 \mathrm{~F}$-choline PET/ $\mathrm{CT}$ in prostate cancer patients with biochemical recurrence: influence of androgen deprivation therapy and correlation with PSA kinetics. J Nucl Med. 2013;54:833-40.

12. Marzola MC, Chondrogiannis S, Ferretti A, et al. Role of $18 \mathrm{~F}$ choline PET/CT in biochemically relapsed prostate cancer after radical prostatectomy: correlation with trigger PSA, PSA velocity, PSA doubling time, and metastatic distribution. Clin Nucl Med. 2013;38:e26-8. 